\title{
ANÁlISE SOCIOAMBIENTAL DO PARQUE ECOLÓGICO DA LAGOA DA MARAPONGA DENTRO DO CONTEXTO DA CIDADE DE FORTALEZA, CE, BRASIL
}

\author{
Nayara Santos da Silva ${ }^{1}$ \\ Anderson Nonato de Freitas ${ }^{2}$ \\ Fábio Perdigão Vasconcelos ${ }^{3}$ \\ Márcia Barbosa Martins ${ }^{4}$
}

\section{Resumo}

Os sistemas lacustres são mananciais de grande valor, tanto para a sociedade como para o ambiente onde se inserem, principalmente pelas contribuições microclimáticas, pelo potencial turístico, paisagístico, de lazer, de pesca artesanal, e pelo suprimento hídrico, entre outros. No entanto, a prática de algumas atividades irregulares vem comprometendo esses sistemas ambientais. Desta forma, foram analisados os aspectos socioambientais da Lagoa da Maraponga, localizada no setor sudoeste da cidade de Fortaleza, pelas discussões que envolvem a inserção da mesma na criação de um parque ecológico, através do Decreto Municipal No 21.349/91, de 3 de maio de 1991, e tendo em vista a sua importância ecológica, econômica e social, no contexto de Fortaleza. Na primeira parte do trabalho foram discutidos os procedimentos metodológicos e operacionais, que serviram como suporte para a concretização da pesquisa, posteriormente foram realizadas as análises e discussões do estudo, e nas considerações finais destacou-se a necessidade de integração dos diversos agentes da sociedade, como governo e habitantes, para um melhor estudo, compreensão e atuação a cerca das mais variadas formas de uso e ocupação do Parque Ecológico da Lagoa da Maraponga, onde prevalece o abandono, a degradação e o desrespeito à legislação ambiental.

Palavras-Chave: Análise socioambiental; lagoa; parque ecológico; Fortaleza.

\begin{abstract}
The lake systems are sources of great value both for society and for the environment in which they operate mainly by contributions microclimate, the potential for tourism, landscape, leisure, fishing, and the water supply, among others, however, practice some irregular activities is committing these environmental systems. Thus, we chose to analyze the environmental aspects of Maraponga Lagoon, located in the southwest sector of the city of Fortaleza, the discussions involving the insertion of the same in creating an Ecological Park, through the Municipal Decree No. 21.349/91 of 3 May 1991, and in view of its ecological, economic and social, in the context of Fortaleza. In the first part of the study were discussed

\footnotetext{
${ }^{1}$ Mestranda do Programa de Pós-Graduação em Geografia da Universidade Estadual do Ceará - UECE. Bolsista da Fundação de Desenvolvimento Científico e Tecnológico do Estado do Ceará - FUNCAP. E-mail: nayara.geo@gmail.com

2 Graduando do Curso de Geografia da Universidade Estadual do Ceará - UECE. Bolsista de IC/PROVIC/UECE. E-mail: andernfreitas@gmail.com

${ }^{3}$ Professor Associado do Programa de Pós-Graduação em Geografia da Universidade Estadual do Ceará UECE. E-mail: fabioperdigao@gmail.com.

${ }^{4}$ Doutoranda do Programa de Meio Ambiente da Universidade Estadual do Rio de Janeiro - UERJ. Bolsista da Fundação Carlos Chagas Filho de Amparo à Pesquisa do Estado do Rio de Janeiro - FAPERJ. E-mail: $\underline{\text { marciabm@gmail.com }}$
} 
methodological and operational procedures, which served as support for the completion of the survey, were subsequently carried out the analyzes and discussions of the study, and the concluding remarks emphasized the need to integrate the various actors in society, as government and residents to better study, understanding and action about the most varied forms of occupation and use of the Ecological Park of Maraponga Lagoon where we observe the abandonment, degradation and disrespect of environmental legislation.

Keywords: Environmental analysis; ecological park; lake; Fortaleza City.

\section{Introdução}

O Parque Ecológico da Lagoa da Maraponga, Fortaleza/CE, foi criado em decorrência de grandes manifestações populares que ocorreram na década de 1990, pressionando o poder público a tomar medidas que minimizassem o avanço desordenado da especulação imobiliária sobre os recursos ambientais do local, principalmente a Lagoa da Maraponga e sua área verde de entorno. Os moradores locais e grupos de ecologistas se uniram com a finalidade de impedir a construção de um polo de lazer particular, que destruiria uma área verde em suas margens.

Na documentação de criação do parque ecológico constam afirmações de que houve, e ainda há, intervenções inadequadas e pressões urbanas não sustentáveis, sendo necessária à existência de uma unidade de conservação (UC) na tentativa de garantir a integridade dos sistemas ambientais, até mesmo em núcleos fortemente urbanizados. No entanto, é necessária a legalização e oficialização dessas áreas no âmbito do Sistema Nacional de Unidades de Conservação da Natureza - SNUC (BRASIL, 2000), de forma que as medidas de conservação, manejo e físcalização possam ser tomadas pelos órgãos competentes.

Atualmente o Parque Ecológico da Lagoa da Maraponga encontra-se em situação de abandono pelo poder público, contrapondo-se à real necessidade de sua existência, que tem como objetivos a realização de pesquisas científicas, o desenvolvimento de atividades de lazer, lócus de atividades de educação e de interpretação ambiental, de recreação em contato com a natureza e de turismo ecológico.

A população local tem realizado protestos nesta área, principalmente em relação à construção de conjuntos habitacionais e de empreendimentos particulares que estão ocupando o entorno da lagoa, agravando ainda mais a situação de desamparo no sentido de preservação do local. Existem ainda os problemas relacionados à poluição com o lixo e esgotos (VASCONCELOS; CORIOLANO; SOUZA, 1996). O parque ecológico permanece bem aquém do que foi idealizado em seus objetivos no ano de sua criação em 1991.

A pesquisa abordou as questões que envolvem a criação do parque, bem como suas precariedades, as consequências e impactos do processo de uso e ocupação que se intensificou nas últimas décadas no seu entorno.

\section{Procedimentos metodológicos e operacionais}

Após a delimitação da área de estudo, a pesquisa foi segmentada em três etapas: a pesquisa de informações preliminares, pesquisa de campo e de gabinete. Durante a primeira 
fase houve o levantamento bibliográfico de informações relacionadas às características cartográficas, ambientais e hidrológicas da área de estudo, através de consultas em trabalhos acadêmicos e técnicos, livros e revistas, que proporcionaram maior conhecimento social e ambiental do parque ecológico, destacando as causas e consequências do seu processo de uso e ocupação.

A base teórica da pesquisa utilizou as contribuições da Compartimentação Geoambiental do Estado do Ceará realizada pela Fundação Cearense de Meteorologia e Recursos Hídricos - FUNCEME, em 2009, tendo em vista que seus procedimentos privilegiaram a síntese e correlações interdisciplinares. Por meio de modelos sistêmicos, introduziram a variável ambiental ao processo de organização territorial. Outra obra utilizada foi o Diagnóstico Geoambiental do Município de Fortaleza, também de 2009, necessária à compreensão dos sistemas ambientais da área e suas formas de uso e ocupação.

Foram utilizadas aerofotografias de 1972, pertencentes à Secretaria Municipal de Infraestrutura - SEINF, além de imagens e mapas mais recentes da área, para uma melhor interpretação e comparação do processo de uso e ocupação do entorno da Lagoa da Maraponga.

As pesquisas de campo foram essenciais para checagem das informações da primeira etapa. Outra função importante foi a comparação das informações obtidas em cartas e imagens com a realidade local onde se insere o parque ecológico. Foi também realizado um registro fotográfico da referida área.

$\mathrm{Na}$ terceira etapa, de gabinete, após a junção e integração dos dados obtidos na primeira e segunda fases, foi realizada a interpretação dos dados, a construção de mapas e imagens para proceder a análise socioambiental do Parque Ecológico da Lagoa da Maraponga.

\section{Resultados}

a) Localização da Área de Estudo

O Parque Ecológico da Lagoa da Maraponga localiza-se no bairro de mesmo nome (Figura 01), margeado pela Av. Godofredo Maciel, no sudoeste da cidade de Fortaleza, com uma área de 31 hectares (SEMACE, 2013). A paisagem local é bastante diversificada, com a presença de uma vegetação mais densa de coqueiros, mangueiras e cajueiros que se associam a uma vegetação rasteira, que se contrapõem com os sítios, residências, grandes empresas e conjunto habitacionais que descaracterizaram a paisagem natural ao longo do tempo.

O parque ecológico está inserido na microbacia B-3.4, da bacia do Rio Cocó, sendo a lagoa da Maraponga alimentada por águas pluviais de escoamento superficial e de galerias, esgotos e pelos riachos Mondubim e Maraponga. O riacho Maraponga apresenta uma extensão de 4,2 Km, alimentando também a lagoa Uirapurú, no bairro do Itaperí (ANA.BANCO MUNDIAL.PROÁGUA NACIONAL.COGERH, 2010). 


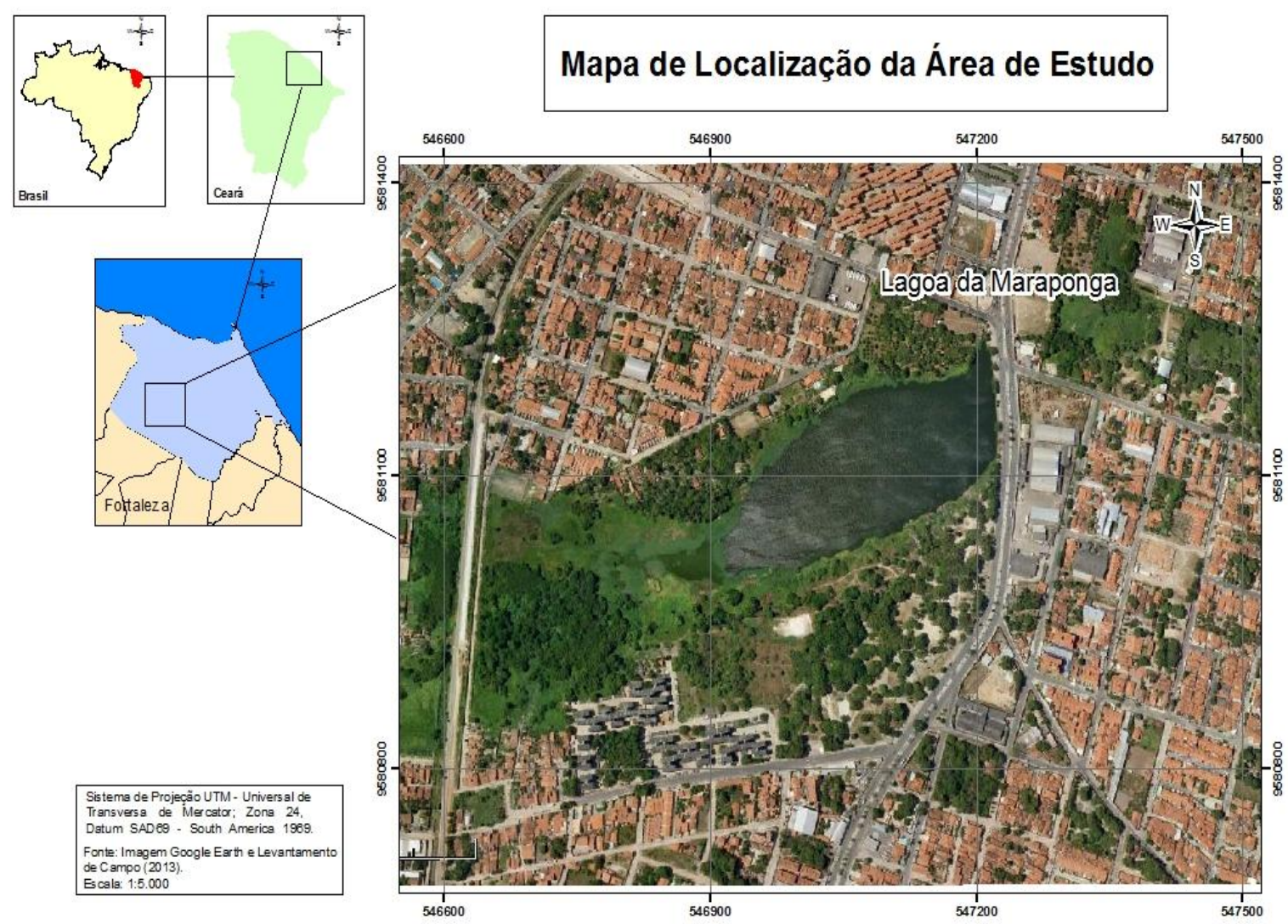

Figura 01. Mapa de Localização da Área de Estudo.

Fonte: Imagem Google Earth, 2009, adaptado pelos autores, 2013.

b) Uma breve contextualização do Parque Ecológico da Lagoa da Maraponga

As unidades de conservação (UCs) da natureza são espaços ambientalmente protegidos e referidos na Lei $\mathrm{n}^{\circ}$ 9.985/2000 que dispõe sobre o Sistema Nacional de Unidades de Conservação da Natureza - SNUC, definido como:

Art. $2^{\circ}$ Para os fins previstos nesta Lei, entende-se por:

I - unidade de conservação: espaço territorial e seus recursos ambientais, incluindo as águas jurisdicionais, com características naturais relevantes, legalmente instituído pelo Poder Público, com objetivos de conservação e limites definidos, sob regime especial de administração, ao qual se aplicam garantias adequadas de proteção; (BRASIL, 2000)

Com isso pode-se observar que a definição de unidade de conservação engloba não apenas elementos como fauna e flora, mas todos os recursos ambientais, como a atmosfera, águas superficiais e subterrâneas, elementos da biosfera, etc. Seguindo essa linha de pensamento, pode ser entendida a importância das áreas protegidas por lei.

As UCs foram divididas em duas categorias: as de Proteção Integral, que tem o intuito de manter os ecossistemas livres de interferência antrópica; e as de Uso Sustentável, que tem 
como objetivo utilizar os recursos ambientais renováveis de forma sustentável. (DANTAS, 2011)

$\mathrm{Na}$ esfera federal, as UCs são administradas pelo Instituto Chico Mendes de Conservação da Biodiversidade - ICMBio. Em relação à esfera estadual, a criação de UCs no Estado do Ceará teve início a partir da década de 1980 com o Parque Ecológico do Rio Cocó (LIRA, 2006). Algumas unidades estaduais são administradas pelo Conselho de Políticas e Gestão do Meio Ambiente - CONPAM, e outras são gerenciadas pela Universidade Regional do Cariri - URCA (SEMACE, 2013a).

A Superintendência Estadual do Meio Ambiente - SEMACE relata que, em Fortaleza, existem 13 unidades municipais protegidas por lei, sendo que oito pertencem à categoria de Área de Conservação de Uso Sustentável, e cinco como áreas que não se enquadram nas categorias do SNUC. Dentre essas cinco, tem-se o Parque Ecológico da Lagoa da Maraponga, criado pelo Decreto Municipal No 21.349/91, de 3 de maio de 1991, classificado como um ecossistema lacustre.

Na Tabela I pode ser visto que Fortaleza, na esfera política municipal, tem apenas o Parque Ecológico da Lagoa da Maraponga como UC, representando uma pequena área se comparado às outras unidades localizadas em outros municípios.

Tabela I. Unidades de Conservação Municipais no Estado do Ceará.

\begin{tabular}{|c|c|c|}
\hline Nome da UC & Área (ha) & Município(s) \\
\hline \multicolumn{3}{|c|}{ UC de Uso Sustentável } \\
\hline Apa da Lagoa da Bastiana & $\begin{array}{r}\text { Informação } \\
\text { indisponível }\end{array}$ & $\begin{array}{l}\text { Perímetro Urbano do Município de } \\
\text { Iguatu }\end{array}$ \\
\hline Apa da Praia de Maceió & $1.374,1$ & $\begin{array}{l}\text { Litoral Oeste do Município de } \\
\text { Camocim }\end{array}$ \\
\hline Apa da Praia de Ponta Grossa & 558,67 & $\begin{array}{l}\text { Litoral Nordeste Do Município de } \\
\text { Icapuí }\end{array}$ \\
\hline Apa de Balbino & 250,0 & $\begin{array}{l}\text { Litoral Leste do Município de } \\
\text { Cascavel }\end{array}$ \\
\hline Apa de Canoa Quebrada & 4000,0 & Nordeste do Município de Aracati \\
\hline Apa de Maranguape & 5521,52 & Maranguape \\
\hline Apa de Tatajuba & 3.775 & Camocim \\
\hline Apa do Manguezal da Barra Grande & $1.260,31$ & Icapuí \\
\hline \multicolumn{3}{|c|}{ UCs não previstas no SNUC } \\
\hline Jardim Botânico de São Gonçalo & 19,80 & São Gonçalo do Amarante \\
\hline Parque Ecológico da Lagoa da & 19,00 & Sobral \\
\hline
\end{tabular}




\begin{tabular}{|l|r|l|}
\hline Fazenda & 31,00 & Fortaleza \\
\hline $\begin{array}{l}\text { Parque Ecológico da Lagoa da } \\
\text { Maraponga }\end{array}$ & 634,50 & Juazeiro do Norte \\
\hline Parque Ecológico das Timbaúbas & $\begin{array}{r}\text { Informação } \\
\text { indisponível }\end{array}$ & Acaraú \\
\hline Parque Ecológico de Acaraú & \\
\hline
\end{tabular}

Fonte: SEMACE, 2013a

Entretanto, no estudo realizado por Lira (op.cit), existe um embate no que se refere à gestão do Parque Ecológico da Lagoa da Maraponga, pois este está regulado por duas leis, a Lei Municipal $n^{\circ}$ 6.833, de 18 de abril de 1991 e o Decreto Estadual no 21.349 de 03 de maio de 1991. Isso faz com que haja uma complicação na administração do parque, pois não se sabe ao certo quem deve assumir a responsabilidade administrativa e legal sobre o mesmo.

Outro agravante no que se refere à gestão é que a lei municipal não foi regulamentada, já o Decreto Estadual delimitou a área a ser desapropriada para o parque, mas não houve efeito legal. Desta forma, não há uma gestão ativa no parque tornando-o vulnerável as ações antrópicas indevidas.

c) Análise Socioambiental do Parque Ecológico da Lagoa da Maraponga

O Parque Ecológico da Lagoa da Maraponga, de acordo com a SEMACE (2013b), apresenta uma área de 31 ha, sendo um dos espelhos d'água mais belos de Fortaleza, no entanto, apresenta diferentes problemas ambientais e sociais, como ocupações indevidas e poluição por águas servidas, que vêm afetando a qualidade do sistema lacustre, repercutindo diretamente nos aspectos socioambientais das comunidades de baixa renda inseridas em suas margens, normalmente ocupando áreas de riscos.

O processo de urbanização na cidade de Fortaleza foi muito intenso nos últimos 50 anos. Vasconcelos (2005) afirma que:

"O crescimento populacional de Fortaleza acelerou-se a partir da década de 1960, quando a cidade contava com uma população de apenas 470.778 habitantes, passando a mais de dois milhões de habitantes no ano 2000. Analisando globalmente, podemos afirmar que em apenas 40 anos a cidade de Fortaleza multiplicou sua população por 4,17." (VASCONCELOS, 2005).

Esse crescimento foi de forma desordenada e, em muitas vezes, irregular do ponto de vista legal, sendo praticamente inevitável o processo de degradação ambiental. No bairro da Maraponga o crescimento urbano também ocorreu como em outros bairros da cidade, também de maneira desordenada e sem respeito aos ambientes naturais existentes, como o caso da área da Lagoa da Maraponga e seu entorno, onde foi preciso a criação de um parque ecológico para interferir na invasão urbana no local. 
Apesar de mais de duas décadas de criação do parque, a área em questão ainda sofre com o adensamento urbano ao seu redor. A falta de uma legislação específica, de um plano de manejo e de um mapeamento do local com suas delimitações legais torna a área e seu entorno desprotegidos e vulneráveis ao crescimento urbano.

Durante a pesquisa foi realizada uma análise comparativa espaço-temporal do parque ecológico, entre os anos de 1972 e 2011, através da interpretação comparativa de fotografias aéreas e imagens de satélite, como mostram as figuras 02 e 03 . Essas figuras mostram a espacialização da realidade urbana, no período de tempo analisado.

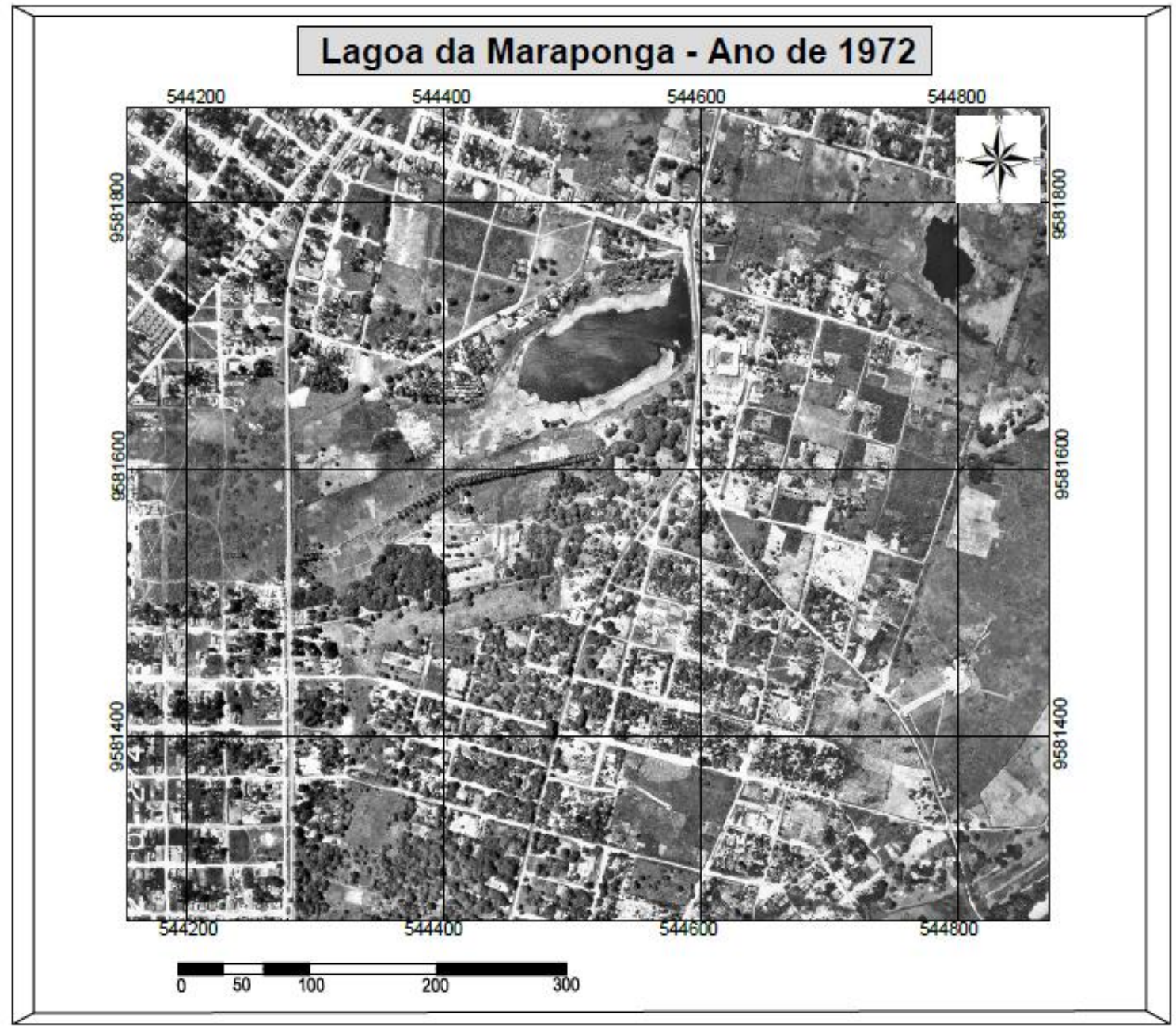

Figura 02. Área referente ao Parque Ecológico da Lagoa da Maraponga em 1972. Fonte: Aerofotografia cedida pela SEINF, 2012. Adaptado pelos Autores, 2013. 


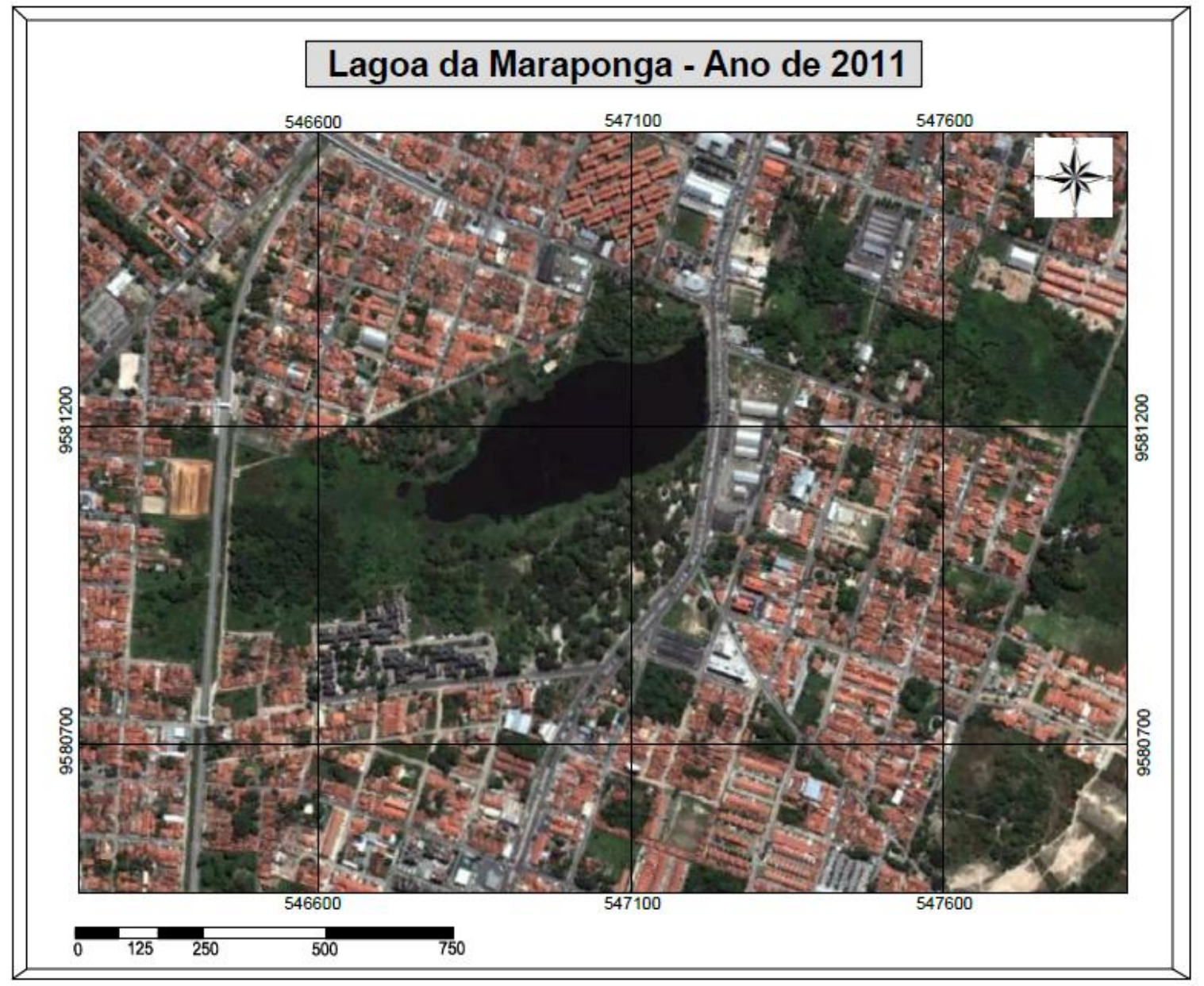

Figura 03. Área referente ao Parque Ecológico da Lagoa da Maraponga em 2011. Fonte: Imagem Google, 2011. Adaptado pelos Autores, 2013.

A comparação entre as figuras mostra que em 1972 existia grande quantidade de espaços vazios ou de cultivo no entorno da Lagoa da Maraponga. As ocupações se davam, em sua maioria, por pequenas casas, arruamentos não pavimentados, ou sítios bem distribuídos e descentralizados. Os setores noroeste e sudoeste da área começavam a ser habitados por residências, ao contrário das regiões nordeste e sudoeste, em grande parte desocupadas.

$\mathrm{Na}$ imagem de 2011 nota-se um crescente adensamento urbano na adjacência imediata do atual parque ecológico, com consequente estreitamento de ruas e maior aglomerado de quadras de casas. Houve intensificação do processo de verticalização, diminuição das áreas verdes, criação de conjuntos habitacionais em espaços antes vegetados e ocupação às margens dos afluentes da lagoa da Maraponga. Portanto a paisagem no entorno do parque ecológico ganhou novos aspectos espaciais com o passar dos anos, sendo que boa parte dos "habitats" naturais de plantas e animais foram destruídos.

A comparação entre as figuras confirma que, durante um período de 39 anos, houve um intenso crescimento urbano no entorno do parque ecológico, o que caracteriza a incompatibilidade da existência de uma unidade de conservação com uma área intensamente urbanizada. Destaca-se que o processo de urbanização tende a ser inevitável, principalmente em longos períodos de tempo, como é o caso da referida análise. A urbanização pode ser 
conciliada com a proteção ambiental somente se realizada após análises e planejamentos urbanos adequados, evitando impactos adversos ao meio socioambiental.

Neste caso, como afirma Christoffoletti (1993):

“a urbanização gera impactos que refletem principalmente no funcionamento do ciclo hidrológico, pois interfere nos percursos e locais de armazenamentos das águas, gerando novas formas de transferência na área urbanizada, além da intervenção em áreas ambientalmente irregulares e dos aspectos sociais." (CRISTOFFOLETTI, 1993).

Lira (op. cit.) destacou alguns critérios de análise dos problemas do Parque Ecológico da Lagoa da Maraponga, dos quais se destacam:

- As ocupações irregulares: mesmo estando regularizada em termos fundiários, pois houve ressarcimento pecuniário junto à empresa proprietária, existem ocupações irregulares no interior do parque;

- Existência de Diploma Legal de criação: o parque possui apenas um decreto de desapropriação, o que não implica na sua criação efetiva e isso não impediu a existência do parque até os dias de hoje, apesar de impedir um avanço maior do crescimento urbano sobre a sua área;

- Integração da População: falta participação ativa da população, por carência de um conselho gestor ou consultivo para a gestão do parque, mesmo considerando as pressões realizadas junto ao poder público para a desapropriação da área referente ao atual parque ecológico;

- Infraestrutura e instrumentos de gestão do Parque: a infraestrutura é precária e está abandonada pelas autoridades, não possuindo uma sede administrativa e nem um centro de visitantes; não existe um plano de manejo e nem de ação emergencial;

- Tipos de Usos do Parque: mesmo sendo caracterizado pela prefeitura municipal como Polo de Lazer, os usos são bem diferentes do que dispõe a Lei $n^{\circ}$ 9.985/00, para a realização de pesquisas científicas, desenvolvimento de atividades de educação e interpretação ambiental, de recreação em contato com a natureza e de turismo ecológico. Observa-se que, aos domingos, o parque é ocupado por banhistas e vendedores ambulantes que utilizam a lagoa e suas margens de maneira inadequadas: práticas de pescaria, atividades comerciais impróprias, despejos de esgotos, dentre outras.

De acordo com o Movimento ProParque, em uma reportagem ao Jornal Diário do Nordeste (2011), algumas ações podem ajudar na recuperação do Parque Ecológico, como saneamento básico das áreas de influência direta e indireta; eliminação de práticas que propiciam os processos erosivos; conscientização da população sobre a importância de preservar a vegetação ciliar; retirada da população das áreas de risco de inundações e promoção da educação ambiental para a população local que frequenta o parque. 


\section{Considerações finais}

Observou-se que a criação do Parque Ecológico da Lagoa da Maraponga foi propiciada pela mobilização da população local na década de 1990, em meio a um cenário de possível apropriação e destruição dos recursos naturais inseridos da área. No entanto, a pesquisa concluiu que referente aos aspectos de conservação, tanto dos sistemas ambientais como da infraestrutura local, o parque apresenta sérios problemas ambientais, estando degradado ambientalmente.

Destacam-se, principalmente, os impactos causados no entorno decorrentes do crescimento urbano acelerado e do descaso dos gestores públicos e da população. Não houve, ao longo do tempo, uma fiscalização pelos órgãos governamentais do processo de ocupação da área. Imóveis foram construídos em áreas de preservação permanente e em áreas de risco.

A falta de políticas públicas eficientes de urbanização que contemplassem a necessidade de ocupação do solo com a preservação natural de ambientes frágeis agravou os processos de degradação e os efeitos deletérios dos impactos adversos dela decorrentes.

Outros fatores que contribuíram para a degradação ambiental dessa unidade de conservação foram à ausência de programas de educação ambiental; baixo nível de organização social da população local; ausência de planejamento urbano; além dos conflitos entre o Poder Público Estadual e Municipal em relação às responsabilidades administrativas sobre o parque ecológico.

Portanto, em relação às unidades de conservação, faz-se necessário o ato normativo declaratório, ou seja, definir legalmente a quem cabe administrar essa unidade de conservação, se o Poder Estadual ou o Municipal.

A normatização do Parque Ecológico da Lagoa da Maraponga permitirá o controle e a vigilância de todas as possíveis atividades desenvolvidas e possibilitará a elaboração de uma base cartográfica com a delimitação geográfica da área. Além disso, será possível instalar o Conselho Consultivo como prevê a Lei do SNUC, que ajudará na gestão dos conflitos existentes e na garantia do bom funcionamento dessa unidade de conservação, incluindo programas adequados de uso público.

\section{Bibliografia}

ANA.BANCO MUNDIAL.PROÁGUA NACIONAL.COGERH. Revisão do Plano de Gerenciamento das águas da Bacia Metropolitana e Elaboração dos Planos de Gerencia mento das águas das bacias do litoral, Acaraú e Coreaú, no Estado do Ceará. Fase 1: Estudos Básicos e Diagnóstico. Bloco I: Produção de Informações Técnicas. Relatório de Tarefas 2 - RT2 BACIAS METROPOLITANAS. Contrato 029/2009/COGERH. Março/2010.

BRASIL. LEI N. ${ }^{\circ} 9.985$, de 18 de julho de 2000. Institui o Sistema Nacional de Unidades de Conservação da Natureza (SNUC). Disponível em: < http://www.planalto.gov.br/ccivil_03/leis/19985.htm >. Acesso em: 25 abr. 2013. 
CHAVES, V.; LIMA, P. C. C.. Um panorama do parque ecológico lagoa da Maraponga e o perfil da população que o frequenta. Disponível em: < http://connepi.ifal.edu.br/ > Acesso: 30 abr. 2013.

CHISTOFFOLETTI, A. Meio ambiente e urbanização tropical. In: Santos, M. et al. (Org) Natureza e sociedade de hoje: Uma leitura geográfica. São Paulo: ED Hucitec, 1993.

FORTALEZA. Decreto Municipal N. ${ }^{\circ} 21.349 / 1991$. Cria a Lagoa da Maraponga. FORTALEZA. Lei Municipal N. ${ }^{\circ} 6.833$, de 18 de abril de 1991. Cria o Parque Ecológico da Lagoa da Maraponga.

FUNDAÇÃO CEARENSE DE METEOROLOGIA E RECURSOS HÍDRICO (FUNCEME). Compartimentação Geoambiental do Estado do Ceará. Fortaleza, 2009.

Jornal Diário do Nordeste. Lagoa da Maraponga está desprotegida. Abr. 2011. Disponível em: <http://diariodonordeste.globo.com/>. Acesso em: 30 abr. 2013.

LIRA, C. F. S. L. A Implementação de Unidades de Conservação de Proteção Integral: O Caso do Parque Ecológico da Lagoa da Maraponga/Ceará. 2006. Dissertação (Mestrado em Desenvolvimento e Meio Ambiente)- PRODEMA, Fortaleza, 2006.

SEMAM. Inventário Ambiental de Fortaleza: Diagnóstico Versão Final. PMF. nov. 2003.

SEMACE. Biodiversidade. Unidades de Conservação. abr. 2013a. Disponível em: < www.semace.ce.gov.br > Acesso em: 30 abr. 2013.

SEMACE. Parque Ecológico da Lagoa da Maraponga. abr. 2013b. Disponível em: < www.semace.ce.gov.br >. Acesso em: 30 abr. 2013.

PILATI, L. C.; DANTAS, M. B.; LEITE, J. R. M. (Org.). Direito Ambiental Simplificado. São Paulo: Saraiva, 2011.

VASCONCELOS, F. P. Gestão Integrada da Zona Costeira - Ocupação antrópica desordenada, erosão assoreamento e poluição ambiental do litoral. Fortaleza: Premius, 2005. v. 1,87 p.

VASCONCELOS, F. P.; CORIOLANO, L. N. M. T.; SOUZA, M. J. N. de. Análise ambiental e sócio econômica dos sistemas lacustres litorâneos do município de Fortaleza (Ceará-Brasil). In: REUNIÃO ANUAL DA SBPC, 48., 1996, PUC, São Paulo, 1996. Resumos. 